\title{
THE DIPLOIDISATION OF POLYPLOID WHEAT
}

\author{
RALPH RILEY \\ Plant Breeding Institute, Cambridge
}

Received 25.viii.6o

\section{INTRODUCTION}

ALlopolyploIDs are usually considered to have originated from species-hybrids in which there was little or no meiotic chromosome pairing because of the structural dissimilarities of the chromosome sets of the parental species. The same structural distinctions are also held to be responsible for the absence of multivalents in the derived polyploids, since they would limit heterogenetic associations (Waddington, 1950) between chromosomes of the different basic sets. Indeed, it has been thought that the differential affinity which causes each chromosome to pair with its identical partner may often be so great that only bivalents are formed.

However, an examination of many of the frequently quoted examples of allopolyploid behaviour suggests that the direct origin of polyploids free from heterogenetic multivalents, with their depressing influence on fertility and stability, must be rare. Indeed, the cytologically diploid behaviour which many natural polyploid species display must often have been acquired subsequent to the development of polyploidy.

Hitherto there has been no evidence to show how the cytological diploidisation of a natural polyploid has been achieved. However, recent experimental results with the hexaploid common wheat, Triticum estivum, illustrate the basis of diploidisation in an apparently typical allopolyploid species, and at the same time give an insight into the cytogenetic functioning of a polyploid (Riley and Chapman, 1958b). The purpose of the present paper is to collect, extend and discuss the evidence so far available on the diploidisation of wheat.

\section{THE STRUCTURE OF TRITICUM AESTIVUM}

It may be helpful, at the outset, to outline the cytogenetic composition of Triticum astivum, and so provide a background for the discussion of the meiotic organisation of the species. T. astivum is the name currently applied to the common wheat of agriculture, for long referred to as T. vulgare. The taxonomic validity of these names has been discussed by Bowden (1959).

The polyploid series in the genus Triticum includes diploid, tetraploid and hexaploid species with 14,28 and 42 chromosomes respectively. The haploid set of chromosomes, or genome, of the diploid wheats may be given the symbol A, so that the diploids are genomically AA. The full complement of diploid wheat is also found in the tetraploid $2 \mathrm{C} 2$ 
and hexaploid species (Sears, I948). In most, and possibly all, of the tetraploids the complete set of chromosomes of another diploid species, most probably Agilops speltoides, is combined with the A genome (Riley, Unrau and Chapman, 1958). The second genome is given the symbol B, so that the tetraploid wheats have the constitution AABB.

Hexaploid wheats have the full complement of chromosomes of the tetraploids and to this has been added the full D set of the diploid Agilops squarrosa. Consequently the hexaploid wheats, including $T$. estivum, have the genome constitution AABBDD.

The relationships between the chromosome sets of the wheats and their relatives have been mainly established by the study of meiotic pairing in species hybrids. The presence of a common genome was revealed by the close synapsis of chromosomes of the related sets. That genome analysis has been possible, in this way, must imply that no structural alterations, of sufficient magnitude seriously to interrupt pairing, have occurred since the separation of the sets of chromosomes common to both parents. Thus the genomes of the tetraploid and hexaploid species are in essentially the same state as those of the original diploids from which they were derived.

In hybrids made between the diploid species, which have been involved in the parentage of $T$. estivum, considerable chromosome pairing takes place. Indeed, there is occasionally full pairing to give seven bivalents in the AD hybrid between diploid wheat and $A$. squarrosa and in what is probably the $\mathrm{AB}$ hybrid, between diploid wheat and $A$. speltoides, although the mean frequency for both hybrids is between 3 and 4 bivalents per cell (Sears, I94I; Riley, Unrau and Chapman, I958). Moreover, the attraction between the chromosomes of these parental diploids is so great that, in the synthetic tetraploids derived from the diploid hybrids, heterogenetic multivalents are common (Sears, I94I; Riley, Unrau and Chapman, I958).

However, although their chromosomes are structurally similar, and are still essentially unaltered compared with their condition in the diploids, there is no pairing between the different genomes in hexaploid wheat. Indeed, even in $2 \mathrm{I}$-chromosome haploids of wheat, in which there is no differential affinity to restrict pairing to fully homologous partners, very little heterogenetic synapsis takes place. Consequently the affinity between equivalent chromosomes of the different genomes must have been suppressed or removed.

This anomaly is emphasised by the extremely close genetical relationships between corresponding chromosomes of different genomes, which have been demonstrated by nullisomic-tetrasomic compensation (Sears, I954). This technique involves crossing together $4 \mathrm{I}$-chromosome monosomics and 44-chromosome tetrasomics in which the chromosomes respectively monosomic and tetrasomic are not homologous. Amongst the derivatives of the resulting hybrids it is possible to extract 42 -chromosome plants nullisomic for the chromosome which 
was originally monosomic in one parent, but still tetrasomic for the chromosome originally tetrasomic in the other parent. Where the nullisomic and tetrasomic chromosomes have similar genetic properties, the physiological defects caused by the complete absence of one chromosome are made up by the extra dosage of the other. Such compensation does not occur when the genetic activities of the pairs involved are not alike.

From this work it has been possible to show that the chromosome complement of wheat can be arranged into seven groups each of three pairs (Sears, 1954). Within the groups nullisomic-tetrasomic compensation occurs and there is some equivalence of genetic activity, whereas between groups there is little similarity in activity. Following Huskins (I93I) the term "homœologous" meaning " similar" has been applied to the relationship between non-partner chromosomes in the same group. The term "homologous", meaning the "same", has been retained to describe the relationship between partner chromosomes.

Recently each homœologous group has been shown to have one chromosome pair in each of the three genomes (Sears, 1958). Thus the relationships which have been established presumably imply the recognition, in the genomes of the hexaploid, of corresponding chromosomes from the three original diploid parents.

Thus, the chromosomes of the original diploid parents of wheat are sufficiently similar to be capable of allosyndetic conjugation in hybrids. Moreover they have undergone no major structural modifications since their incorporation in the polyploids. In addition the similarity in genetic activity of corresponding chromosomes is retained. Yet thereis no meiotic pairing between homœologous chromosomes from different genomes. This species may, therefore, be seen to exemplify rather vividly the problem of the mechanism of diploidisation in a polyploid. What is known of the history and structure of chromosomes of the species contrasts so remarkably with the pattern of pairing observed at meiosis. Consequently it may be that the demonstration of the basis of the diploid-like behaviour in wheat will help to clarify related problems in other species.

\section{MATERIAL}

(i) The haploids

This work has principally involved the study of various kinds of haploids in Triticum astivum variety Holdfast $(2 n=42)$. T. astivum is a hexaploid so it would perhaps be strictly correct to use the term " polyhaploid ". However, for simplicity, particularly in describing haploid plants with aneuploid numbers the basic term " haploid" seems preferable. It is applied to describe plants with essentially the gametic chromosome constitution.

Some of the haploids arose in material being used to add specific pairs of chromosomes of rye, Secale cereale, to the full complement of wheat chromosomes (Riley and Chapman, 1958a). Others occurred in the progenies of plants being used to 
replace single pairs of wheat chromosomes by single pairs from rye (Riley and Bell, 1958). The derivations of all the haploids studied are shown in table $\mathrm{I}$.

All the haploids arose, by female parthenogenesis, from parents in which there had been either 20 or 2 I bivalents as well as some univalents at meiosis. It is reasonable to suppose that the chromosomes in bivalents had segregated regularly and the univalents irregularly. Consequently, it can be assumed that a haploid,

TABLE I

The origins of the haploids

\begin{tabular}{|c|c|c|c|}
\hline Plant & $\begin{array}{l}\text { Chrom. } \\
\text { no. }\end{array}$ & Parent genotype & $\begin{array}{l}\text { Phenotype or } \\
\text { chromosome complement }\end{array}$ \\
\hline \multicolumn{4}{|l|}{ Euhaploids } \\
\hline 1 & 21 & $21^{\prime \prime} w+3^{\prime} r$ & euhaploid \\
\hline 2 & $2 \mathrm{I}$ & $2 \mathrm{I}^{\prime \prime} w+\mathrm{I}^{\prime} r$ & euhaploid \\
\hline 3 & $2 \mathrm{I}$ & $2 \mathbf{r}^{\prime \prime} w+\mathbf{1}^{\prime} r$ & euhaploid \\
\hline 4 & 21 & $2 \mathbf{r}^{\prime \prime} w+\mathbf{r}^{\prime} r$ & euhaploid \\
\hline 5 & 21 & $2 \mathrm{r}=w+\mathbf{I}^{\prime} r$ telocentric & euhaploid \\
\hline 6 & 21 & segregating population* & euhaploid \\
\hline 7 & 21 & $20^{\prime \prime} w+\mathbf{I}^{\prime} w+\mathrm{I}^{\prime} r$ telo. & no telo. present \\
\hline 8 & $2 \mathrm{I}$ & $\begin{array}{l}2 \mathrm{I}^{\prime \prime} w+{ }^{\prime} r \text {, long }+ \text { short } \\
\text { telo. II }\end{array}$ & no telo. present \\
\hline 9 & 21 & $2 \mathrm{r}^{\prime \prime} w+3^{\prime} r$ & euhaploid \\
\hline 10 & $2 \mathrm{I}$ & segregating population* & euhaploid \\
\hline II & $2 \mathrm{I}$ & segregating population* & euhaploid \\
\hline & 21 & $21^{\prime \prime} w+\mathrm{I}^{\prime} r$ & euhaploid \\
\hline \multicolumn{4}{|l|}{ Nullihaploids } \\
\hline nulli-I 2 & 20 & $20^{\prime \prime} w+\mathbf{I}^{\prime} w \mathbf{I}+\mathbf{I}^{\prime} r \mathrm{IV}$ & close to I mono. \\
\hline $\begin{array}{l}\text { nulli-XVII } \\
\text { nulli-VII }\end{array}$ & $\begin{array}{l}20 \\
20\end{array}$ & $\begin{array}{l}20^{\prime \prime} w+\mathrm{I}^{\prime} w X V I I+\mathbf{I}^{\prime} r I V \\
20^{\prime \prime} w+\mathrm{I}^{\prime} w \mathrm{~V}+\mathbf{I}^{\prime} r I I I\end{array}$ & close to XVII mono. \\
\hline nulli-V 2 & 20 & $20^{\prime \prime} w+\mathbf{I}^{\prime} w V+\mathrm{I}^{\prime} r \mathbf{I I}$ & All very short, well tillered, \\
\hline nulli-V 3 & 20 & $20^{\prime \prime} w+\mathrm{I}^{\prime} w \mathrm{~V}+\mathrm{I}^{\prime} r \mathrm{III}$ & with very small, compact \\
\hline nulli-V 4 & 20 & $20^{\prime \prime} w+\mathrm{I}^{\prime} w \mathrm{~V}+\mathrm{I}^{\prime} r \mathrm{III}$ & spikes, matching nulli-V \\
\hline nulli-V 5 & 20 & $\begin{array}{l}2 \mathrm{O}^{\prime \prime} w+\mathrm{I}^{\prime} w \mathrm{~V} \% \text { pollinated } \\
\text { by Aeg. caudata }\end{array}$ & \\
\hline 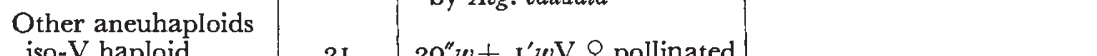 & $2 \mathrm{I}$ & $2 \mathrm{O}^{\prime \prime} w+\mathrm{r}^{\prime} w \mathrm{~V} q$ pollinated & \\
\hline nulli-I rye-IV & 21 & $20^{\prime \prime} w+\mathrm{I}^{\prime} w \mathbf{I}+\mathrm{I}^{\prime} r \mathbf{I V}$ & $\begin{array}{l}\text { A clear effect of rye IV on } \\
\text { spikelet morphology }\end{array}$ \\
\hline $\begin{array}{l}\text { Addition haploids } \\
\text { rye-II haploid } \\
\text { rye-III haploid }\end{array}$ & $\begin{array}{l}22 \\
22\end{array}$ & $\begin{array}{l}21^{\prime \prime} w+\mathrm{I}^{\prime} r \text { II } \\
21^{\prime \prime} w+\mathrm{I}^{\prime} r \text { III }\end{array}$ & $\begin{array}{l}\text { Like rye II addn. } \\
\text { Like rye III addn. }\end{array}$ \\
\hline & & & $w=$ wheat \\
\hline
\end{tabular}

* In the populations derived, after some generations without selection, from plants with $2 I^{\prime \prime}$ wheat $+7^{\prime}$ rye.

which had the same number of chromosomes as there had been bivalents in its parent, had received chromosomes from bivalents only. Thus, 2I-chromosome haploids, from parents with all the wheat pairs plus a number of unpaired rye chromosomes, must have had the full gametic constitution of wheat and no rye chromosomes. Plants with this constitution, none of which showed any of the phenotypic effects expected from the presence of rye chromosomes, are here called "euhaploids".

A number of 20-chromosome plants occurred in the progenies of parents with 20 wheat bivalents plus a wheat and a rye univalent. The parents had been derived from crosses between 4 I-chromosome plants, monosomic for a specific wheat chromosome, 
and 44-chromosome plants with the disomic addition of a specific rye chromosome to the full wheat complement. Consequently it was known which wheat and which rye chromosomes were unpaired. Further, the wheat chromosome deficient from 20-chromosome " nulli-haploids" corresponded to the one which was monosomic in the original parent. Thus the chromosome composition of the nulli-haploid could be accurately specified.

The wheat monosomics from which the nulli-haploids were ultimately derived were extracted during work with the variety Holdfast. However, chromosome numbering in wheat is based on the designations given to the monosomic lines in the variety Chinese Spring (Sears, 1954). Two of the Holdfast monosomics, I and V, to which nulli-haploids are related, have been checked and confirmed against the Chinese Spring numbering. The chromosome deficient from the other nulli-haploid has been shown by crossing possibly to be chromosome XVII but this has not been finally confirmed. Before its homology with V of Chinese Spring was established chromosome V of Holdfast was known as $\mathrm{HH}$ (Riley and Chapman, I958b; Riley, Chapman and Kimber, 1960 ).

"Addition haploids" with 22 chromosomes were obtained from plants with 2 I wheat bivalents plus a specific rye univalent. They were evidently formed by the parthenogenetic functioning of eggs which had received the rye univalent as well as the regularly segregating wheat chromosomes. Both addition haploids displayed phenotypic features characteristic of the particular rye chromosome present.

One $2 \mathrm{I}$-chromosome haploid was derived from a 42-chromosome parent which was monosomic both for chromosome I of wheat and for chromosome IV of rye. Since it possessed a phenotype characteristic of the presence of the rye chromosome IV, this chromosome must have been included, and chromosome I of wheat excluded. This plant may be conveniently referred to as a nulli-I rye-IV " substitution haploid."

Finally an " iso-V haploid " with 20 normal chromosomes, plus an isochromosome, was obtained when a wheat plant monosomic for chromosome $\mathrm{V}$ was pollinated with the pollen of a $44^{-c h r o m o s o m e ~ r y e ~ c h r o m o s o m e ~ d i s o m i c ~ a d d i t i o n ~ p l a n t . ~ T h e ~ h a p l o i d ~}$ apparently arose from an unfertilised egg which had received, in addition to the 20 normally segregating chromosomes, the isochromosome of the long arm resulting from the misdivision of the chromosome $\mathrm{V}$ univalent.

The euhaploids were collected and examined over a period of five years and the nulli-V haploids over a period of three years.

\section{(ii) Other material}

In testing the effects of each individual wheat chromosome on meiotic pairing use has been made of the series of $2 \mathrm{I}$ monosomic lines developed in $\mathcal{T}$. estivum variety Chinese Spring by Dr E. R. Sears. Other species used in this work were:

Secale cereale L. variety King II $(2 n=\mathrm{I} 4)$.

Egilops longissima Schweinf. and Muschl. $(2 n=14)$.

Agilops speltoides Tausch ligustica Savign. $(2 n=\mathrm{I} 4)$.

Egilops cylindrica Host. var. typica Eig. $(2 n .=28)$.

\section{CHROMOSOME PAIRING IN HAPLOIDS AND HYBRIDS}

All cytological observations were made on Feulgen-orcein prepara. tions. Squashes of pollen mother cells from anthers fixed in acetic alcohol were used in meiotic studies.

Chromosome pairing at first metaphase of meiosis has been studied in all the haploids examined and data from the cells scored have been presented in two ways. The mean pairing per cell (tables 2 and 4) 
shows the general pattern of behaviour of each plant. In addition the same records have been presented as the frequencies of total chromosome associations per cell (tables 3 and 5). The totals of associations in each cell were obtained by summing the number of bivalents, trivalents and quadrivalents. They, therefore, indicate the number of groups of chromosomes within which pairing occurred and the frequency with which various levels of pairing were achieved.

The chromosome pairing in euhaploids provides a standard against which to compare the behaviour of other types of haploid plant. In

TABLE 2

Mean pairing at first metaphase of meiosis in haploids*

\begin{tabular}{|c|c|c|c|c|c|}
\hline Plant & $\begin{array}{l}\text { Chrom. } \\
\text { no. }\end{array}$ & Cells & Bivalents & $\begin{array}{c}\text { Proportion } \\
\text { closed bivalents }\end{array}$ & Trivalents \\
\hline euhaploid I . & $2 \mathrm{I}$ & 100 & $I \cdot 39 \pm 0.09$ & - & 0.07 \\
\hline euhaploid 2 . & $2 \mathrm{I}$ & 100 & $1 \cdot 61 \pm 0.06$ & 0.02 & 0.01 \\
\hline euhaploid 3 . & $2 \mathrm{I}$ & 100 & I.69 50.12 & 0.02 & 0.05 \\
\hline euhaploid 4 . & $2 \mathrm{I}$ & $5^{\circ}$ & $0.60 \pm 0.12$ & - & - \\
\hline euhaploid 5 . & $2 \mathrm{I}$ & $5^{\circ}$ & $0.72 \pm 0.10$ & - & - \\
\hline euhaploid $\overrightarrow{6}$. & $2 \mathrm{I}$ & 50 & $0.90 \pm 0.14$ & - & - \\
\hline euhaploid 7 . & $2 \mathrm{I}$ & $5^{\circ}$ & $\mathrm{I} \cdot 02 \pm 0.09$ & 0.02 & 0.02 \\
\hline euhaploid 8 . & $2 \mathrm{I}$ & $5^{\circ}$ & $0.80 \pm 0.11$ & - & - \\
\hline euhaploid 9 . & 21 & 50 & $0.78 \pm 0.09$ & 0.03 & 0.02 \\
\hline euhaploid io . & $2 \mathrm{I}$ & 50 & $0.72 \pm 0.11$ & 0.03 & 0.04 \\
\hline euhaploid I I . & $2 \mathrm{l}$ & 50 & $0.82 \pm 0.1 \mathrm{I}$ & - & - \\
\hline euhaploid I 2 . & $2 \mathrm{I}$ & 50 & $I \cdot 56 \pm 0 \cdot 16$ & - & 0.04 \\
\hline nulli-I haploid I & 20 & 100 & $0.66 \pm 0.07$ & - & - \\
\hline $\begin{array}{l}\text { nulli-I haploid } 2 \\
\text { nulli-XVII haploid }\end{array}$ & $\begin{array}{l}20 \\
20\end{array}$ & $\begin{array}{r}100 \\
60\end{array}$ & $\begin{array}{l}0.96 \pm 0.08 \\
1.70 \pm 0.06\end{array}$ & $\begin{array}{l}0.01 \\
0.04\end{array}$ & $0 \cdot 02$ \\
\hline iso- $\mathrm{V}$ haploid & $2 \mathrm{I}$ & 100 & $0.90 \pm 0.07$ & - & - \\
\hline nulli-I rye IV haploid & $2 \mathrm{I}$ & 50 & $0.88 \pm 0.05$ & 0.04 & - \\
\hline rye-II haploid. & 22 & 40 & $\mathrm{I} \cdot 25 \pm 0 \cdot 13$ & - & 0.08 \\
\hline rye-III haploid & 22 & 100 & $\mathrm{I} \cdot 0 \mathrm{01} \pm 0.07$ & - & 0.01 \\
\hline
\end{tabular}

* The residue of chromosomes, after those in bivalents and tivalents, were univalents.

the twelve euhaploids examined, the mean bivalent frequency per cell ranged from 0.60 , in euhaploid 4 , to 1.69 in euhaploid 3 . Trivalents were recorded in six plants but the highest mean frequency was only 0.07 per cell. Chromosome pairing was thus very low and the differences between the euhaploids are readily attributable to environmental differences. Mean pairing of this order has been widely reported in 2 I-chromosome haploids of $\mathcal{T}$. estivum (Riley and Chapman, I957), and none of the present plants was at all atypical.

There were never more than five associations of synapsed chromosomes in any euhaploid cell. Indeed the presence of more than three associations was rare and there was never more than one trivalent per cell. 
Thus there was very little pairing in these euhaploids of T. estivum, despite the genetical similarity of homœologous chromosomes and despite the structural similarity of chromosomes of the component genomes. The low level of homœologous pairing (Sears and Okamoto, 1957) in $2 \mathrm{I}$-chromosome euhaploids is even more remarkable than its complete absence from 42-chromosome euploids. In the latter the strong attraction between complete homologues diminishes the possibility of homœologous association, but there can be no differential affinity to

TABLE 3

The distribution of cells with various totals of bivalents plus trivalents in haploids

\begin{tabular}{|c|c|c|c|c|c|c|c|c|c|}
\hline \multirow{2}{*}{ Plant } & \multirow{2}{*}{ Cells } & \multicolumn{8}{|c|}{$\begin{array}{l}\text { Percentage of cells with various } \\
\text { numbers of associations }\end{array}$} \\
\hline & & o & I & 2 & 3 & 4 & 5 & 6 & 7 \\
\hline euhaploid I . & 100 & 15 & 45 & 28 & Io & 2 & o & 0 & o \\
\hline euhaploid 2 : & IOO & I6 & 22 & 46 & I3 & 2 & o & o & o \\
\hline euhaploid 3 . & 100 & 17 & 29 & 30 & 16 & 8 & o & 0 & o \\
\hline euhaploid 4 . & 50 & 60 & 24 & 12 & 4 & o & o & o & o \\
\hline euhaploid 5 . & 50 & 40 & 48 & 12 & o & o & $\mathrm{o}$ & 0 & o \\
\hline euhaploid 6 & 50 & 44 & 34 & 12 & 8 & 2 & o & o & o \\
\hline euhaploid 7 & 50 & $\begin{array}{l}17 \\
18\end{array}$ & 62 & 20 & o & o & o & o & o \\
\hline euhaploid 8 & 50 & $3^{8}$ & 46 & 14 & 2 & 0 & o & o & o \\
\hline euhaploid 9 . & 50 & 38 & 50 & 8 & 4 & o & o & o & o \\
\hline euhaploid Io. & 50 & 42 & 50 & 2 & 6 & 0 & o & o & 0 \\
\hline euhaploid i I & 50 & $3^{6}$ & 50 & 10 & 4 & 0 & o & o & o \\
\hline euhaploid i2: & 50 & 18 & 30 & 36 & 12 & 2 & 2 & o & o \\
\hline nulli-I haploid I & 100 & 46 & 45 & 6 & 3 & 0 & o & o & o \\
\hline nulli-I haploid 2 & 100 & 26 & 54 & I9 & o & I & o & o & o \\
\hline nulli-XVII haploid & 60 & Io & 35 & 29 & I 8 & 5 & o & o & o \\
\hline iso- $\mathrm{V}$ haploid & 100 & 26 & 60 & o & I & o & o & o & 0 \\
\hline nulli-I rye-IV haploid & 50 & 24 & $5^{6}$ & 20 & o & o & o & o & o \\
\hline rye-II haploid. & 40 & 17 & 47 & 27 & 9 & o & o & o & o \\
\hline rye-III haploid & 100 & 19 & 62 & 18 & I & 0 & 0 & 0 & 0 \\
\hline
\end{tabular}

reduce homœologous pairing in euhaploids. Homœologous affinity is thus only weakly expressed in hexaploid wheat.

The two nulli-I haploids and the nulli-XVII haploid fit very well into the range of pairing patterns found in the euhaploids. Consequently the deficiency of chromosomes I and XVII had no major influence on meiosis. It therefore appears that they carry no genes which exercise any significant control over haploid meiosis.

Similarly the nulli-I rye-IV haploid condition did not produce any marked modification of meiosis, compared with the euhaploid state.

Lastly amongst this group of aneuhaploids, the two 22-chromosome plants, with rye chromosomes II and III respectively, did not deviate 
from the narrowly circumscribed behaviour of the euhaploids. The presence of the extra chromosome, in each case, had not affected pairing behaviour, and the rye chromosome was always a univalent.

The striking conclusion, which emerges from this examination of a number of haploids with abnormal genetic constitutions, is that meiosis in wheat seems to follow a course which is narrowly restricted. The overall genetic organisation of meiosis of hexaploid wheat is such that, in plants at the haploid condition, a particular meiotic pattern, with only a slight amount of pairing, occurs. Moreover, even though the haploid genotype is greatly modified by the addition, removal or replacement of particular chromosomes, meiosis still follows the same course. The organisation of meiosis in wheat is, therefore, remarkably stable.

TABLE $_{4}$

Mean chromosome pairing at first metaphase of meiosis in nulli-V haploids.

\begin{tabular}{|c|c|c|c|c|c|c|c|}
\hline \multirow{2}{*}{ Plant } & \multirow{2}{*}{ Cells } & \multirow{2}{*}{ Univ. } & \multicolumn{3}{|c|}{ Bivalents } & \multirow{2}{*}{ Triv. } & \multirow{2}{*}{ Quad. } \\
\hline & & & Rod & Ring & Total & & \\
\hline $\begin{array}{l}\text { nulli-V haploid I } \\
\text { nulli-V haploid } 2 \\
\text { nulli-V haploid } 3 \\
\text { nulli-V haploid } 4 \\
\text { nulli-V haploid } 5\end{array}$ & $\begin{array}{l}75 \\
30 \\
33 \\
44 \\
3^{6}\end{array}$ & $\begin{array}{l}8 \cdot 99 \pm 0 \cdot 53 \\
8 \cdot 00 \pm 0.57 \\
6 \cdot 40 \pm 0 \cdot 39 \\
6 \cdot 46 \pm 0 \cdot 34 \\
6 \cdot 53 \pm 0 \cdot 31\end{array}$ & $\begin{array}{l}3 \cdot 17 \pm 0 \cdot 25 \\
2 \cdot 37 \pm 0 \cdot 20 \\
1 \cdot 94 \pm 0 \cdot 22 \\
2 \cdot 3^{2} \pm 0 \cdot 20 \\
2 \cdot 75 \pm 0 \cdot 23\end{array}$ & $\begin{array}{l}\mathrm{I} \cdot 00 \pm 0.12 \\
0.80 \pm 0.13 \\
\mathrm{I} \cdot 6 \mathrm{I} \pm 0.21 \\
\mathrm{I} \cdot 68 \pm 0.20 \\
0.97 \pm 0.17\end{array}$ & $\begin{array}{l}4.17 \pm 0.28 \\
3.17 \pm 0.22 \\
3.55 \pm 0.31 \\
4.00 \pm 0.22 \\
3.72 \pm 0.24\end{array}$ & $\begin{array}{l}0.86 \pm 0.27 \\
1.80 \pm 0.21 \\
2.00 \pm 0.20 \\
1.73 \pm 0.16 \\
1.83 \pm 0.21\end{array}$ & $\begin{array}{l}0.02 \\
0.07 * \\
0.12 \\
0.09 \\
0.06 * \dagger\end{array}$ \\
\hline
\end{tabular}

* Plus one association of five.

$\uparrow$ Plus one association of six.

There was a startling change, however, when chromosome $\mathrm{V}$ was deficient from the haploid complement (table 4). Nulli-V haploids had means of between 3.17 and 4.17 bivalents per cell. Thus they had more than twice as many bivalents as most euhaploids. Moreover much higher proportions of the bivalents in nulli-V haploids were closed rings.

In addition there were means of from $0 \cdot 86$ to $2 \cdot 00$ trivalents per cell in nulli- $\mathrm{V}$ haploids and generally there were more trivalents in plants of this constitution than there were bivalents in euhaploids. The trivalents were mostly chains, but tri-radials and " pan-handles" also occurred. There were also infrequent chain quadrivalents.

The maximum pairing observed was in a cell with five trivalents, two bivalents and one univalent. By contrast the highest observed in a euhaploid cell was five bivalents and II univalents. Whereas there were none, one, or two associations in most euhaploid cells, many cells had four, five, or six associations in the nulli- $\mathrm{V}$ haploids, and those with none, or only one or two, were very rare.

It is clear, from the contrasts between the nulli- $\mathrm{V}$ and all other haploid conditions, that chromosome $\mathrm{V}$ must carry a gene, or genes, 
with a powerful influence on meiotic pairing. The effect of the presence of the $\mathrm{V}$ gene, in a normal wheat plant, is to diminish associations. This immediately raises the question of the relationships between the chromosomes which pair in its absence. It may be assumed, since the evidence to the contrary is limited (McClintock, 1933; Levan, I942; Reiger, I957), that meiotic chromosome pairing which accompanies chiasma-formation usually takes place between structurally and genetically corresponding segments. The increased pairing in nulli-V haploids must, therefore, imply some segmental homology between the associated chromosomes.

There are two explanations which might account for this segmental homology. First the paired regions might be randomly distributed duplicate segments between which synapsis is normally inhibited.

TABLE 5

The distribution of cells with various totals of bivalents, trivalents, quadrivalents and higher associations in nulli-V haploids.

\begin{tabular}{|c|c|c|c|c|c|c|c|c|c|c|}
\hline \multirow{2}{*}{ Plant } & \multirow{2}{*}{ Cells } & \multicolumn{9}{|c|}{ Percentage of cells with from $0-8$ associations } \\
\hline & & o & I & 2 & 3 & 4 & 5 & 6 & 7 & 8 \\
\hline nulli-V haploid I & 75 & 0 & 0 & 4 & I & 20 & 44 & 26 & 4 & I \\
\hline nulli-V haploid 2 & 30 & o & o & 3 & Io & 17 & 30 & 30 & 10 & o \\
\hline nulli-V haploid 3 & 33 & o & 0 & 0 & 0 & 15 & I 7 & 55 & 10 & 3 \\
\hline nulli-V haploid 4 & 44 & o & o & o & $\mathrm{o}$ & 5 & 27 & $4^{8}$ & 16 & 4 \\
\hline nulli-V haploid 5 & $3^{6}$ & 0 & 0 & 0 & 0 & 6 & $3^{i}$ & 55 & 8 & o \\
\hline
\end{tabular}

Alternatively, the paired regions might be in genetically and cytologically corresponding, homœologous, chromosomes from the different genomes.

One of the most prominent considerations which lends favour to the latter hypothesis is the high frequency of trivalents. There were as many as five in some nulli-V haploid cells. The formation of trivalents is a likely outcome of the association of all three homœologous chromosomes but it is improbable that so much structural triplication should be present, unrelated to polyploidy. Also there were very rarely more than seven associations per cell and this can be satisfactorily explained if pairing occurs almost entirely within the seven homœologous groups and rarely between groups. However a small amount of homology must be postulated between groups to account for the rare cells with a quadrivalent or with eight associations. It is extremely improbable that structural duplications, unrelated to the polyploid nature of the plant, would be so distributed as to cause meiotic pairing which coincides so admirably with that expected from homœologous association. Consequently it seems reasonable to conclude that an important influence of chromosome $\mathrm{V}$ in euhaploids is greatly to restrict pairing between homœologues. It is natural therefore, to 
enquire whether it exercises a similar function in 42-chromosome hexaploid wheat.

Meiosis was examined in 40-chromosome nullisomics of Holdfast wheat which were deficient for both members of the $\mathrm{V}$ pair. These were found to have a multivalent in most cells, and sometimes several per cell (fig. I). Quadrivalents were slightly more common than

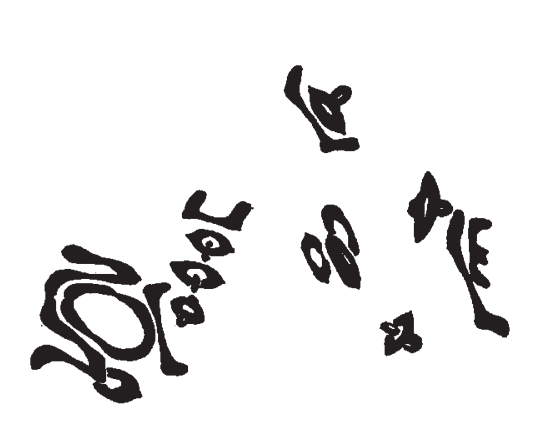

(a)

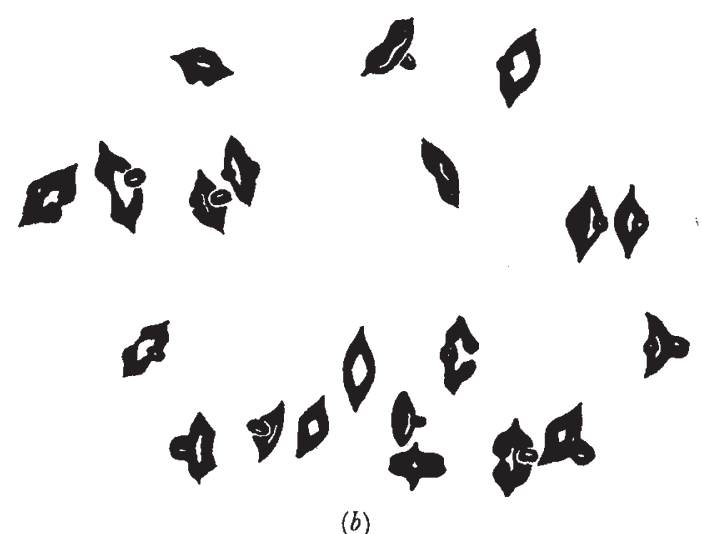

(b)

FIG. 1.-Camera lucida drawings of first metaphase of meiosis in pollen mother cells of T. estivum (a) nullisomic for chromosome $V$ showing 15 bivalents, one ring of four and one chain of six, $(b)$ normal hexaploid showing 21 bivalents. (Present magnification $\times$ I I 50.)

trivalents and there were also associations of five and six chromosomes (table 6). In many cells there were also univalents which were not the residue of odd-number multivalents. The meiotic behaviour of these nullisomics was clearly consistent with the notion that homøeologous pairing was occurring.

TABLE 6

Mean pairing at first metaphase of meiosis in euploid and nulli-V T. æstivum.

\begin{tabular}{|c|c|c|c|c|c|c|c|}
\hline Plant & Cells & Univ. & Biv. & Triv. & Quad. & $5-$ & $6-$ \\
\hline euploid & 200 & 0.14 & 20.93 & - & - & - & - \\
nulli-V & 60 & $\mathrm{I} \cdot 4 \mathrm{I}$ & $\mathrm{I} 7.22$ & 0.47 & 0.59 & 0.02 & 0.05 \\
\hline
\end{tabular}

Thus the absence of chromosome $\mathrm{V}$ changed wheat from a regular and stable bivalent-forming plant, typical of the classical concept of an allopolyploid species, into one behaving more like a segmental allopolyploid or indeed like an autopolyploid. Therefore a genetic mechanism on chromosome $\mathrm{V}$ normally limits pairing in this way, and furthermore, there is no independent system on any other chromosome which can make up for the absence of the V-gene. However, it might be that the critical gene, or genes, on $\mathrm{V}$ form part of a complementary system, involving genes in other linkage groups. Removal of any other chromosome involved in the system would then cause a breakdown 
in the normal organisation of meiosis, similar to that which results from the deficiency of $\mathrm{V}$.

In testing this, use was made of the knowledge that the increased pairing in V-deficient material shows well in hybrids between wheat and rye, Secale cereale, lacking V (Riley, Chapman and Kimber, I959). Hybrids with 27-chromosomes, deficient for any wheat chromosome, can be produced by crossing the appropriate wheat monosomic, as female, with rye. The univalent wheat chromosome is excluded from about three quarters of the embryo sacs of the monosomic parent, so

\section{TABLE 7}

Mean chromosome pairing at first metaphase of meiosis in $\mathrm{T}$. æstivum $\times \mathrm{S}$. cereale hybrids deficient in turn for each wheat chromosome *

\begin{tabular}{|c|c|c|c|c|c|}
\hline $\begin{array}{l}\text { Chromosome } \\
\text { number }\end{array}$ & $\begin{array}{c}\text { Chromosome } \\
\text { deficient }\end{array}$ & Cells & Bivalents & Trivalents & Quadrivalents \\
\hline 28 & 一 & 300 & 0.48 & - & - \\
\hline 27 & I & IOO & O. I I & - & 一 \\
\hline 27 & II & 100 & 0.15 & - & - \\
\hline 27 & III & 100 & $0 \cdot 14$ & 一 & 一 \\
\hline 27 & IV & 100 & 0.37 & $0 \cdot 01$ & 一 \\
\hline 27 & $\mathrm{~V}$ & 200 & $3 \cdot 3^{6}$ & $0 \cdot 88$ & $0 \cdot 08$ \\
\hline 27 & VI & IOO & $0 \cdot 31$ & $一$ & - \\
\hline 27 & VII & 100 & 0.40 & - & - \\
\hline 27 & VIII & IOO & $0 \cdot 3^{2}$ & 0.01 & - \\
\hline 27 & IX & 100 & 0.75 & - & 一 \\
\hline 27 & $\underset{Y T}{X}$ & IOO & $0 \cdot 33$ & O.OI & 一 \\
\hline 27 & XI & IOO & 0.06 & - & - \\
\hline 27 & $\underset{\mathrm{XII}}{\mathrm{XII}}$ & 100 & 0.49 & - & 二 \\
\hline 27 & XIII & 100 & $0 \cdot 12$ & - & - \\
\hline 27 & XIV & 100 & $\begin{array}{l}0.22 \\
0.71\end{array}$ & - & - \\
\hline 27 & $\begin{array}{c}\text { XV } \\
\text { XVI }\end{array}$ & $\begin{array}{l}100 \\
100\end{array}$ & $\begin{array}{l}0.7 \mathrm{I} \\
\mathrm{I} \cdot 00\end{array}$ & - & - \\
\hline $\begin{array}{l}27 \\
27\end{array}$ & XVII & 100 & 0.77 & - & 一 \\
\hline $\begin{array}{l}27 \\
27\end{array}$ & XVIII & 100 & 0.86 & - & - \\
\hline $\begin{array}{l}27 \\
27\end{array}$ & XIX & 100 & 0.47 & 一 & - \\
\hline 27 & $\mathrm{XX}$ & 100 & $0 \cdot 23$ & - & - \\
\hline 27 & XXI & IOO & 0.29 & - & - \\
\hline
\end{tabular}

* The residue of chromosomes, not in bivalents, trivalents or quadrivalents, were univalents.

that both 27- and 28-chromosome hybrids can be obtained from the same parents.

Hybrids were produced between $T$. estivum, Chinese Spring and Secale cereale, deficient in turn for each of the 2I chromosomes of wheat. Examination of first metaphase of meiosis showed that only in the hybrids deficient for chromosome $\mathrm{V}$ was there a serious difference between the pairing of 27- and 28-chromosome plants (table 7). Thus the removal of no other wheat chromosome results in a modification of pairing comparable with that arising from the absence of $\mathrm{V}$. This chromosome is, therefore, unique in having the property of preventing homœologous association.

Simultaneous evidence of the responsibility of chromosome $\mathrm{V}$ for the diploid-like behaviour was provided independently of the present 
work by Sears and Okamoto (1958). In investigating hybrids between T. estivum monosomics and diploid wheat, they found that there was much higher pairing in those hybrids from which chromosome $\mathrm{V}$ was deficient. The increased pairing could only be interpreted as arising from homœologous conjugation. Thus the evidence from Vnullisomics, from nulli-V haploids and from $\mathrm{V}$-deficient hybrids fits together well.

Further information on the localisation of pairing control was obtained from the iso-V haploid plant (table 2). This had 20 normal chromosomes plus the isochromosome for the long arm of $\mathrm{V}$, and was completely deficient for the short arm. Chromosome V is markedly heterobrachial (Sears, 1954) having one arm about twice the length of the other. Meiosis in the iso-V haploid was similar to that in euhaploids, removal of the short arm producing no alteration in pairing. Moreover, $4 \mathrm{I}$-chromosome plants, with $\mathrm{V}$ represented by a monosomic telocentric for the long arm, regularly form 20 bivalents and a univalent at meiosis, and never make multivalents. In addition 42-chromosome plants disomic for the long telocentrics form only bivalents. Consequently the effective region of the chromosome is not restricted to the short arm. Thus it may be that a part of the long arm alone is responsible, or that pairing limitation results from the joint activity of genes in both arms.

It has not so far been possible to obtain a plant with the telocentric for the short arm of $\mathrm{V}$ but deficient for the long arm. However, the short telocentric can be maintained in 42-chromosome plants, which also have one complete chromosome. No segregants deficient for the complete chromosome are produced, presumably because of the poor competitive ability of pollen grains carrying the short telocentric. Nevertheless plants with the complete chromosome $\mathrm{V}$ plus the short telocentric can be pollinated by another species and use made of the embryo sacs with the telocentric to produce hybrid individuals deficient for the long arm. Also normal monosomics, and plants disomic for telocentrics of the long arm can be used to make other hybrids for comparison. Hybrids with the complete chromosome $\mathrm{V}$, deficient for $\mathrm{V}$, and with either the long or the short arm telocentric, can thus be compared.

The most satisfactory comparisons would be based on hybrids involving a diploid such as rye or A. longissima, as the male parent, but results are so far available only from crosses based on Egilops cylindrica, an allotetraploid with the genomic constitution CGDD. Meiotic pairing has been compared in the four types of hybrid (table 8), and there were almost seven bivalents per cell in normal 35-chromosome hybrids, carrying the complete chromosome V. This was due to the two D genomes derived by each parent from $A$. squarrosa (McFadden and Sears, 1946). However, the only multivalents were the rather rare trivalents representative of the intergenome pairing found in euhaploids of wheat. 
Hybrids deficient for $\mathrm{V}$ had a considerably greater frequency of multivalents with no reduction in the bivalent frequency. Thus the effects of chromosome $\mathrm{V}$, on meiotic pairing, were detectable in these hybrids, involving a polyploid, just as they were in those with rye (table 7) and with $A$. longissima (table 9), both diploid species. Nevertheless the increase in pairing was less dramatic in this example perhaps because of the disomic condition of the $\mathrm{D}$ genome chromosomes or because of the possible effect of genetic diploidising influences in the A. cylindrica genotype.

There was a clear difference between the hybrids carrying the long and the short arm telocentrics respectively. Those deficient for the long arm much more nearly approached the behaviour of the

\section{TABLE 8}

The mean pairing at first metaphase of meiosis in hybrids of $\mathrm{T}$. æstivum $\times \mathrm{A}$. cylindrica with the complete chromosome complement of $\mathrm{T}$. æestivum, or with $\mathrm{T}$. æstivum deficient for chromosome $V$ or either its long or its short arm

\begin{tabular}{|c|c|c|c|c|c|c|c|}
\hline $\begin{array}{l}\text { Status of } T \text {. aestivum } \\
\text { complement }\end{array}$ & $\begin{array}{l}\text { Chrom. } \\
\text { No. }\end{array}$ & Cells & Univ. & Biv. & Triv. & Quad. & $5-$ \\
\hline $\begin{array}{l}\text { complete } \\
\text { deficient short } \mathrm{V} \\
\text { deficient long } \mathrm{V} \\
\text { deficient } \mathrm{V} \text {. }\end{array}$ & $\begin{array}{l}35 \\
35 \\
35 \\
34\end{array}$ & $\begin{array}{r}40 \\
50 \\
50 \\
100\end{array}$ & $\begin{array}{l}20 \cdot 89 \\
19 \cdot 62 \\
16 \cdot 40 \\
13 \cdot 16\end{array}$ & $\begin{array}{l}6 \cdot 80 \\
7 \cdot 18 \\
6 \cdot 44 \\
7 \cdot 41\end{array}$ & $\begin{array}{l}0 \cdot 17 \\
0 \cdot 34 \\
I \cdot 26 \\
I \cdot 36\end{array}$ & $\begin{array}{l}- \\
-46 \\
0.36\end{array}$ & $\begin{array}{l}- \\
- \\
0 \cdot 02 \\
0 \cdot 10\end{array}$ \\
\hline
\end{tabular}

$\mathrm{V}$-deficient hybrids, especially in the high frequency of multivalents. By contrast those deficient for the short arm were little different from the euploid hybrids with the complete chromosome, having no multivalents higher than trivalents.

From this it seems that the diploid-like meiotic behaviour of wheat is principally controlled by one or more genes on the long arm of chromosome V. As a note of caution, however, it should be indicated that the long arm-deficient hybrids with $A$. cylindrica did not fully reach the level of pairing found in hybrids lacking the complete chromosome. However, the difference was small, a mean of $2 \cdot 24$ fewer chromosomes paired, and may have no genetic significance.

\section{ORIGIN OF THE DIPLOIDISING MECHANISM}

There is no direct evidence concerning the origin of the pairing control exercised by chromosome $\mathrm{V}$, so that discussion must be mainly speculative. First of all, however, an indisputable preliminary point is that chromosome $\mathrm{V}$ is in the $\mathrm{B}$ genome of hexaploid wheat (Sears, 1958) and consequently it has a homologue in tetraploid wheat. Hybrids between tetraploid and hexaploid wheats do not produce, amongst their derivatives, any segregants with intergenome associations. Consequently there must be alleles with similar effects at both levels of polyploidy. 
The diploidising effect of chromosome $\mathrm{V}$ may result from an activity which the chromosome also performed in its original diploid background. Alternatively gene mutation subsequent to the incorporation of the chromosome in polyploid wheat may have altered its activity. If chromosome $\mathrm{V}$ caused diploid-like behaviour without modification, then amongst the probable contributors of the B genome a species should be found producing the same effect as $\mathrm{V}$.

The B genome probably came to polyploid wheat from a species of the Sitopsis section of Egilops (Sarkar and Stebbins, 1956). This

\section{TABLE 9}

The mean chromosome pairing at first metaphase of meiosis in the hybrids T. æstivum $\times$

A. speltoides and T. æstivum $\times$ A. longissima, with and without chromosome $V$ of T. æstivum.

\begin{tabular}{|c|c|c|c|c|c|c|c|c|}
\hline Plant & $\begin{array}{l}\text { Chrom. } \\
\text { number }\end{array}$ & $\begin{array}{c}\text { Chrom. } \\
\text { V }\end{array}$ & Cells & Univ. & Biv. & Triv. & Quad. & $5-$ \\
\hline$\times A$. speltoides & 28 & present & $5^{\circ}$ & $6 \cdot 04$ & $6 \cdot 64$ & I 88 & $0 \cdot 76$ & - \\
\hline$\times A$. speltoides & 28 & present & 50 & $3 \cdot 40$ & $6 \cdot 14$ & $2 \cdot 20$ & $\mathrm{I} \cdot 3 \mathrm{O}$ & 0.04 \\
\hline$\times A$. speltoides & 27 & absent & 30 & $6 \cdot 13$ & $5 \cdot 23$ & $I \cdot 76$ & $\mathrm{I} \cdot 23$ & 0.03 \\
\hline$\times A . s_{t}$ & 27 & abs & 30 & $6 \cdot 90$ & $6 \cdot 10$ & I 33 & 0.93 & 0.03 \\
\hline$\times A$. longissima & 28 & present & 100 & $23 \cdot 90$ & I 96 & - & - & - \\
\hline$\times A$. longissima & 27 & absent & 100 & $7 \cdot 50$ & $7 \cdot 58$ & $0 \cdot 70$ & 0.56 & - \\
\hline$\times A$. longissima & 27 & absent & 100 & $9 \cdot 80$ & $6 \cdot 45$ & 0.87 & 0.41 & - \\
\hline
\end{tabular}

includes four species, all diploids, namely $A$. speltoides, A. bicornis, $A$. longissima and $A$. sharonensis, although the last two should perhaps be lumped (Tanaka, 1955). Riley, Unrau and Chapman (1958) have already pointed out that $A$. speltoides behaves quite differently from the other Sitopsis species in hybrids with tetraploid wheat. Hybrids with $A$. speltoides have high pairing at meiosis and show a breakdown in the isolation of homoologous chromosomes. This does not happen in hybrids with any other Sitopsis species in which, indeed, there is very little chromosome pairing at all. Superficially, therefore, the species other than $A$. speltoides seem to produce effects on chromosome pairing analogous to those caused by wheat chromosome $\mathrm{V}$.

An attempt was therefore made to understand the relationships between the effect on homøologous pairing of chromosome $\mathrm{V}$ and of the genotypes of two Sitopsis species (Riley, Kimber and Chapman, 196r). For this purpose hybrids, with and without chromosome V, were made between T. estivum and either A. speltoides or A. longissima, in the way previously described for chromosome-deficient wheat-rye hybrids.

$A$. speltoides and $A$. longissima are very similar in chromosome structure, and hybrids between them have good meiotic pairing although they differ by a reciprocal translocation. However, their 
hybrids with $T$. astivum behaved quite differently (table 9). In 28-chromosome hybrids with $A$. speltoides there was very high pairing, with many trivalents and quadrivalents. The normal barrier between homœologues was broken down. There was little difference between these and the 27-chromosome $A$. speltoides hybrids, deficient for chromosome $\mathrm{V}$. Thus it appears that the $A$. speltoides genotype inhibits the influence of chromosome $\mathrm{V}$, so that the absence of $\mathrm{V}$ produces no effect in the presence of the $A$. speltoides genotype.

There was little chromosome pairing in 28-chromosome hybrids with A. longissima, consequently this genotype does not suppress the $\mathrm{V}$ effect. By contrast 27-chromosome, V-deficient, hybrids with $A$. longissima showed considerable homœologous pairing, absence of $\mathrm{V}$ from the hybrid acting in the same way as its absence from a haploid. Significantly, therefore, the $A$. longissima genotype cannot compensate for the absence of $\mathrm{V}$ in preventing homœologous association and so it clearly does not function in the same way as chromosome V. A. bicornis similarly cannot compensate for the deficiency of $\mathrm{V}$ (Riley, unpublished). Thus, assuming $A$. sharonensis to equal $A$. longissima, all the Sitopsis species which do not suppress the $\mathrm{V}$ effect are also not equivalent to $\mathrm{V}$ in activity. It is unlikely, therefore, that the $\mathrm{V}$ condition came, without modification, from the donor of the $\mathrm{B}$ genome in which it might conceivably have been responsible for restricting pairing between small structural duplications. On the contrary the effect is probably produced by one or more loci on the critical chromosome, altered or unmasked by mutation subsequent to the formation of the first polyploid.

The nature of the mutation involved is open to a number of possible explanations, but it is most readily conceived as occurring at a single locus, although a more complex origin cannot be excluded. The locus on $\mathrm{V}$, responsible for the restriction of intergenome pairing, may also be concerned with the differences in the meiotic behaviour, in hybrids, of $A$. speltoides and the other Sitopsis species. On this hypothesis the three different pairing effects would be due to alleles at the same locus.

Alternatively a mutant on $\mathrm{V}$ may have arisen at a locus at which A. speltoides and the remaining species are not different. The cause of their different behaviour in hybrids would then reside elsewhere in their genotypes. This second hypothesis has certain disadvantages if, as is likely, A. speltoides is the $\mathbf{B}$ genome donor. For then mutations elsewhere must be postulated to have overcome the inhibitory influence which the $A$. speltoides genotype has over the normal functioning of the chromosome $\mathrm{V}$ mechanism.

Thirdly A. longissima and $A$. speltoides may differ at the $\mathrm{V}$ locus, A. speltoides carrying a gene there similar in action to that on $\mathrm{V}$ of wheat. However, the effect of this may be inhibited in $A$. speltoides by genes elsewhere in the genotype, mutation of which in the polyploid removed the inhibition, so that the $\mathrm{V}$ condition took over the regulation of the diploid-like behaviour. 
If, however, the regulatory effect of $\mathrm{V}$ arose, as postulated, by mutation either on $\mathrm{V}$ or elsewhere, then the significant gene, or genes, must subsequently have been fixed by selection. This probably occurred in the tetraploid wheats, all of which are diploidised. The already adjusted genotype was then passed on to the hexaploids. Selection in the tetraploid would readily favour genetic variants which precluded the production of homøologous multivalents, the cause of lower fertility and irregular genetic segregation.

\section{FUNCTIONING OF THE CHROMOSOME $\vee$ GENE}

There is little difference between the frequency and distribution of the chiasmata linking paired chromosomes in euploid and nullisomic $\mathrm{V}$ plants. Thus the effect of chromosome $\mathrm{V}$ is probably not directly related to chiasma formation. In addition, although the analysis of early prophase of meiosis is unsatisfactory in wheat, the chromosomes of euploid plants seem to be fully paired throughout their length. Consequently, there are probably few regions with unsatisfied pairing where genetical alteration in the size of the pairing blocks, or the intimacy of association, could give rise to the increased conjugation observed in the absence of $\mathrm{V}$.

It may be, therefore, that the influence of chromosome $\mathrm{V}$ is on the forces which attract chromosomes together and which initiate pairing. In euploid wheat the attraction between complete homologues, which are more or less identical structurally, is sufficient to cause very regular bivalent formation. However, there is less attraction between homœologues, which are somewhat divergent in structure, and the attraction is normally insufficient to cause them to pair. Chromosome $\mathrm{V}$ thus appears to control pairing by reducing attraction to a level below which homœologous pairing cannot be completed. It seems likely, in view of the increased effect in its absence, that the chromosome $\mathrm{V}$ gene inhibits positively acting processes, responsible for pairing, which are determined elsewhere in the genotype.

The effect of chromosome $\mathrm{V}$ could thus be described as the genetic enhancement of differential affinity (Darlington, 1937). Its development was probably dependent upon the occurrence, in the raw polyploid, of greater attraction between homologues than between homœologues. This is presumably a system, therefore, which could not evolve in a true autopolyploid where each chromosome is equally attracted to a number of identical homologues.

\section{THE DIPLOIDISATION OF POLYPLOIDS}

There are many polyploid species of undoubted hybrid origin which only form bivalents at meiosis. These are the allopolyploid forms of classical theory, which ideally arise from hybrids between two or more species, in which the chromosomes of the parents are so different that 
they are unable to pair, or form only a small number of loosely associated bivalents. Chromosome doubling in such hybrids supposedly gives rise to polyploids in which each chromosome pairs only with its identical partner. Meiosis is therefore regular and there is disomic inheritance although often with many duplicate genes.

To determine the likelihood of the fullest expression of allopolyploid behaviour occurring directly, simply as a consequence of chromosome doubling in hybrids, well established examples of allopolyploidy can be considered. Two comparisons are possible, the first being made between the chromosome behaviour of the natural polyploid species and that of the synthetic polyploid derived from hybrids between its putative diploid parents. Secondly, chromosome pairing can be compared in haploids of tetraploid species and in the initial hybrid between the putative diploid parents. That is, the established polyploid can be compared with the "raw" polyploid, or the true haploid with the synthetic haploid.

The hybrid between $\mathcal{N}$ icotiana sylvestris and Nicotiana tomentosiformis, close relatives of the diploid parents of Nicotiana tabacum, a tetraploid, has a mode of three and a maximum of seven bivalents (Goodspeed, I934). By contrast the haploid $\mathcal{N}$. tabacum normally has a mode of zero and a maximum of three bivalents (Lammerts, I934). This suggests that the diploidisation of tobacco was apparently not automatically achieved on chromosome doubling.

Similar methods may be applied to the tetraploid species Poa annua which probably combines the genomes of the two diploids $P$. infirma and $P$. supina (Tutin, I952, I957). $P$. annua forms only bivalents at meiosis (Hovin, 1958) but in the synthetic tetraploid derived from the hybrid between the putative parents there were multivalents (Tutin, I957). Thus $P$. annua has evolved towards the diploid-like condition, rather than achieving it directly with polyploidy.

Again, Brassica juncea, a tetraploid, shows evidence of diploidisation subsequent to the origin of the polyploid since there is more pairing in hybrids between its putative parents, $B$. campestris and $B$. maja, than in haploid $B$. juncea (Ramanujam and Srinivasachar, I943).

A further example is provided by the tetraploid New World cottons, in one species of which, Gossypium barbadense, the haploids rarely form bivalents. However the $\mathrm{F}_{\mathrm{I}}$ hybrid between species related to the original diploid parents, $G$. arboreum and $G$. thurberi, averages eight bivalents per cell and the raw tetraploid has some multivalents (Skovsted, I937; Beasley, I942).

Finally, taking a species closely related to wheat, the haploid of Egilops ovata, a tetraploid, has considerably less pairing than the hybrid between its parents (Matsumura, I940; Kihara, 1937). It is therefore clear that in other polyploid species, in addition to wheat, completely regular meiosis, with pairing restricted to identical partners, and disomic inheritance, has developed after the origin of the polyploid condition. 
Indeed it is probably often not realised that some of the synthetic forms, which have been regarded as good examples of allopolyploid behaviour, are not completely stable at meiosis and make multivalents. Into this class must go Raphano-brassica (Richharia, I937) and Primula kewensis (Upcott, I 939).

Further, the use of synthetic polyploids to illustrate the immediately stable behaviour of allopolyploids must be invalid when one of the parents is already polyploid (Stebbins, I950). The reason for this is that a genetic condition leading to the elimination of multivalents, and effective in the new synthetic, may already be present in the polyploid parent. This difficulty is illustrated by the $\mathcal{T}$. estivum $\times$ Secale cereale (Triticale) and $T$. estivum $\times$ A. longissima allopolyploids, in which multivalents are never formed in the presence of wheat $V$, but do occur in its absence (Riley, unpublished).

It must not be supposed, however, that the direct origin of a purely bivalent-forming polyploid, from diploids, can never occur. For example the haploid of Brassica napus has about the same meiotic pairing as the $F_{\mathrm{I}}$ hybrid between its probable parents $B$. campestris and $B$. olerace (Olsson and Hagberg, I955; U, I935). Also the raw tetraploid obtained from the hybrid is meiotically regular, like the natural B. napus (Frandsen, 1947). In addition, the synthetic Galeopsis tetrahit produced by Müntzing (I930) from $G$. pubescens and $G$. speciosa appears to have been immediately regular and stable at meiosis. Nevertheless, although such stable forms can occasionally occur they seem to be less common. Most forms which are sufficiently similar to form viable hybrids also have chromosomes capable of conjugation in their allopolyploid derivatives.

Since the diploidisation of polyploids appears to have been common in the evolution of higher plants the processes involved may be enquired into. Two hypotheses have been proposed but, until the wheat example, little direct evidence was available. One suggested possibility was that the basic diploid chromosome sets, combined in the polyploid, diverged from one another in structure (Darlington, I937; Stebbins, I950). Structural alterations which impeded meiotic conjugation between homœologous chromosomes, from different genomes, were selected and became homozygous because of their influence on fertility through reduced multivalent formation. The accumulation of many such structural alterations, it was considered, would eventually lead to the complete differentiation of the chromosomes of the different genomes and so to a purely bivalent-forming meiotic pattern. Such processes would inevitably be very slow and the young polyploid species, for much of its early and uncertain existence would be hampered by considerable infertility.

Although it is hard to prove, this process may have had some significance in polyploid evolution. However, its limited importance is perhaps illustrated by the frequency with which, by meiotic pairing in hybrids, the chromosomes of diploids can be matched with related sets 
in polyploids. In this way the restricted extent of changes in structure, from the original diploid condition, can be revealed in polyploids which have clearly undergone diploidisation.

The diploidisation of polyploids may also be achieved by the selection of genetic variants with modified chromosome pairing. The situation in $\mathcal{T}$. estivum is an example of this, with selection for fertility and genetic stability, in the original tetraploid, probably leading to the fixation of the mutant condition. Such a process, with a simply inherited control over the patterns of conjugation, would be rapid and precise and the newly arisen polyploid would be exposed to the minimum period of reproductive inefficiency.

The basis of meiotic behaviour is not established in any other allopolyploid as it is in wheat. However, in the light of the results with wheat, work by Lammerts (I934) on haploids of Nicotiana tabacum, a diploidised tetraploid, may perhaps be tentatively re-interpreted. Lammerts found that a haploid from coral, a mutant form heterozygous for a translocation, had much higher pairing than haploids from normal parents. Apparently the coral haploid had arisen from a gamete with a duplication-deficiency segregation of the chromosomes involved in the translocation. Nevertheless, the extra pairing was much more than could be ascribed solely to the presence of the duplicated segment. Lammerts interpreted this as non-homologous pairing in a physiologically abnormal individual. It seems quite possible, alternatively, that the additional pairing involved homœologouschromosomes between which conjugation was normally inhibited by the activity of genes on the segment rendered deficient by the segregation of the coral translocation. This suggests, therefore, that there may be, in $\mathcal{N}$. tabacum, a genetic regulation of the diploid-like behaviour similar to that in wheat.

A further example of genetic diploidisation, suggested to me by Mr G. Kimber, can perhaps be demonstrated in the tetraploid New World cottons. In the triploid hybrids between such a tetraploid, for example Gossypium barbadense, and either of its diploid ancestors, there is good pairing at meiosis between chromosomes of the genomes common to the diploid and the tetraploid. Consequently no major accumulation of structural modifications can have occurred in the tetraploid. Moreover, there is reasonably good pairing in hybrids between the two diploid ancestors, but in haploids of the tetraploid there is virtually no pairing (Beasley, 1942). Since the lack of pairing between homœologues in the haploid cannotbe entirely due to structural differentiation it presumably has a genetic basis.

Thus it can be seen that in those polyploid species, inevitably crop plants, which have been most widely investigated, evidence of genetical diploidisation can be discerned. Indeed it may well be that systems like that in wheat will prove to be the usual method of achieving a diploid-like pattern of behaviour. However the combination of genetical and chromosome-structural diploidisation may also occur, 
and some purely bivalent-forming types certainly arise directly without subsequent modification.

The preceding discussion has been concerned with polyploids which regularly form bivalents at meiosis and have disomic segregation ratios, that is polyploids in which each chromosome pairs with its single identical partner. It is important to distinguish these species from others which, while commonly forming only bivalents at meiosis, have polysomic segregation. In such species four or more partner chromosomes conjugate at random in pairs.

Such a case has been well documented in the hexaploid Phleum pratense (Nordenskiöld, 1945, 1953), European forms of which make 2I bivalents but show hexasomic inheritance. A similar example is provided by Lotus corniculatus, a tetraploid, in which cyanogenetic activity is inherited tetrasomically but which rarely forms multivalents at meiosis (Dawson, I94I).

This type of organisation, whilst affording regular chromosome segregation and high fertility, has less significance in evolution than that of polyploids with disomic segregation. In the latter, alleles at some of the duplicated loci can mutate away from their original function without detriment, since the function is continued at homœologous loci. The outline of this process has been illustrated in polyploid wheat by comparing the pattern of induced mutations in diploid, tetraploid and hexaploid species (MacKey, 1958). Thus evolutionary exploration can take place in a polyploid with disomic inheritance in a way not possible in a bivalent-forming autopolyploid, since in the latter selection of a mutant allele must lead to the eventual elimination of the pre-existing allele and to loss of the original function.

\section{THE DIPLOIDISATION OF WHEAT AND WHEAT BREEDING}

The introduction of genetic variation from many primitive species related to wheat is prevented because, in hybrids, wheat chromosomes do not pair with the chromosomes of the alternative parent. Riley and Chapman (1958b) reasoned that this lack of pairing may often be due to the same activity of chromosome $\mathrm{V}$ which prevents pairing between the wheat genomes. Intergeneric hybrids deficient for $\mathrm{V}$ were therefore investigated (Riley, Chapman and Kimber, 1959). Under these conditions increased pairing occurred, some of which must have associated wheat chromosomes and the chromosomes of the alternative parents, $S$. cereale and A. longissima. This was illustrated by the formation of quadrivalents, combining three wheat homœologues and the matching foreign chromosome, in hybrids deficient for $\mathrm{V}$, although there was no allosyndetic pairing when $\mathrm{V}$ was present. Consequently removing chromosome $\mathrm{V}$ disposes of the initial barrier to the incorporation of much foreign variation in wheat.

Secondly, 4o-chromosome, V-nullisomic plants which undergo intergenome pairing offer a means of repatterning the chromosome 
structure of wheat. Recombination between homœologues leads to the formation of translocations relative to the original structure. The new states can be stabilised when made homozygous and chromosome $\mathrm{V}$ is restored, and the lines so produced may possess agricultural advantages either directly or as a consequence of the altered segregations following their use in hybridisation. Finally, intergenome pairing may make it possible to obtain beneficial genes with dose effects duplicated or triplicated on homœologous chromosomes, although they could normally be no more than disomic.

Knowledge of the diploidisation of $T$. estivum can clearly extend the horizons of wheat breeding in direct and practical ways. However, further investigation is needed before appropriate methods can be devised for handling the material involved.

\section{SUMMARY}

I. The absence of one chromosome, number $\mathrm{V}$, greatly modifies the meiotic pairing of haploids and nullisomics of wheat, Triticum astivum $(2 n=6 x=42)$. It is concluded that this chromosome carries a genetic structure responsible for the diploid-like meiotic and genetical behaviour of the hexaploid. In the presence of chromosome $\mathrm{V}$ the genetically and structurally equivalent chromosomes of the different genomes of wheat do not pair, but this isolation breaks down in its absence.

2. Evidence from a series of hybrids with Secale cereale shows that no similar modification of pairing occurs in the absence of any of the other 20 chromosomes. In addition results from hybrids between wheat and Egilops cylindrica, deficient either for the complete chromosome $\mathrm{V}$ or for its long or short arm separately, indicate that the control is exercised by the long arm alone. Thus the genetic system is very localised and it may be that a single locus is responsible.

3. None of the diploid species from which chromosome $\mathrm{V}$ may have been derived produces a genetic effect on pairing like that of $\mathrm{V}$. This suggests that the diploidising function of $\mathrm{V}$ arose by mutation after the origin of polyploidy in wheat, probably at the tetraploid level. It could have resulted either from mutation on $\mathrm{V}$ itself or from an unmasking mutation elsewhere. The mutant would probably have been favoured by selection for the improved fertility and genetic stability to which it led.

4. It is suggested the meiotic regulation operates through the modification of pairing attractions during prophase.

5. Many polyploids have acquired a purely bivalent-forming meiotic regime, with disomic inheritance, subsequent to the development of polyploidy. It seems likely that this may often have been the outcome of genetical, rather than chromosome-structural, modifications.

6. Manipulation of the genetic control of pairing, exercised by 
chromosome $\mathrm{V}$, may have important consequences for wheat improvement, both in the incorporation of variation from other species, and in the reorganisation of the genetic structure of wheat itself.

Acknowledgments.-It is a pleasure to acknowledge the help of my two colleagues, Mr Victor Chapman and Mr Gordon Kimber. Valuable technical assistance was given by Mrs K. M. Pauley, Mr H. A. Torrens and Mr T. E. Miller.

\section{REFERENCES}

BEASLEY, J. O. 1942. Meiotic chromosome behaviour in species, species hybrids, haploids and induced polyploids of Gossypium. Genetics, 27, 25-54.

BOWDEN, W. M. 1959. The taxonomy and nomenclature of the wheat, barleys, and ryes and their wild relatives. Canad. F. Bot., 37, 657-684.

Darlington, c. D. 1937. Recent Advances in Cytology, 2nd Edition. Churchill, London.

DAwson, C. D. R. 194I. Tetrasomic inheritance in Lotus corniculatus L. F. Genet., 42, 49-72.

FRANDSEN, K. J. 1947. The experimental formation of Brassica napus L. var. oleifera D.C. and Brassica carinata Braum. Dansk. Bot. Arkiv, 12, I-16.

GERSTEL, D. U., AND PHILLIPS, L. L. 1958. Segregation of synthetic amphiploids in Gossypium and Nicotiana. Cold Spring Harbor Symp. quant. Biol., 23, 225-237.

GOodsPEED, T. M. 1934. Nicotiana phylesis in the light of chromosome number, morphology and behaviour. Univ. Calif. Publ. Bot., 17, 369-398.

Hovin, A. W. 1958. Meiotic chromosome pairing in amphihaploid Poa annua L. Amer. F. Bot., 45, 131-138.

HUSKINS, C. L. I931. A cytological study of Vilmorin's unfixable dwarf wheat. 7. Genet., 25, I $13-124$.

KIhARA, H. 1937. Genomanalyse bei Triticum und Agilops. VII. Mem. Coll. Agr. Kyoto Univ., 4I, I-6r.

LAMMERTS, W. E. I934. On the nature of chromosome association in $\mathcal{N}$. tabacum haploids. Cytologia, 6, 38-50.

LEVAN, A. 1942. Studies on the meiotic mechanism of haploid rye. Hereditas, 28, I 77-1 23.

MCCLINTOCK, B. 1933. The association of nonhomologous parts of chromosomes in the mid-prophase of Zea mays. Zeitschr. Zellf. Mikr. Anat., 19, 191-237.

MCFADDEN, E. S., AND SEARS, E. R. 1946. The origin of Triticum spelta and its freethreshing hexaploid relatives. F. Hered., 37, 81-89, 107-1 16.

MACKEY, J. 1958. Mutagenic response in Triticum at different levels of ploidy. Proc. First Int. Wheat Genet. Symp., 88-1og.

matsumura, s. 1940. Inducierte Haploidie und Auto-tetraploidie bei Egilops ovata L. Bot. Mag., Tokyo, 54, 404-413.

MÜNTZING, A. 1930. Uber Chromosomenvermehrung in Galeopsis-Kreuzungen und ihre phylogenetische Bedentung. Hereditas, 14 , I53-1 72.

NoRdenskiöld, H. 1945. Cytogenetic studies in the genus Phleum. Acta Agric. Suecana, I, I-I37.

NORDENSKIÖLD, H. 1953. A genetical study in the mode of segregation in hexaploid Phleum pratense. Hereditas, 39, 469-488.

olsson, G. AND HAGBERG, A. 1955. Investigations on haploid rape. Hereditas, 4I, 227-237.

RAMANUJAM, S. AND SRINIVASACHAR, D. 1943. Cytogenetic investigations in the genus Brassica and the artificial synthesis of B. juncea. Ind. F. Genet. Pl. Breed., 3, 73-88.

REIGER, R. 1957. Inhomologenhaarung und Meiosenblauf bei Haploiden Formen von Antirrhinum majus L. Chromosoma, 9, 1-38. 
RichHARIA, R. H. 1937. Cytological investigation of Raphanus sativus, Brassica oleracea, and their $\mathrm{F}_{1}$ and $\mathrm{F}_{2}$ hybrids. F. Genet., 34, 19-44.

RILEy, R. AND BELL, G. D. H. 1958. The evaluation of synthetic species. Proc. First Int. Wheat Genet. Symp., I6 I-I 79.

RILEY, R. AND chapman, v. 1957. Haploids and polyhaploids in Egilops and Triticum. Heredity, II, I 95-207.

RILEY, R., AND CHAPMAN, v. I $958 a$. The production and phenotypes of wheat-rye chromosome addition lines. Heredity, 12, 301-315.

RILEY, R., AND chapman, v. 1958 $b$. 'Genetic control of the cytologically diploid behaviour of hexaploid wheat. Nature, Lond., I82, 713-715.

RILEY, R., CHAPMAN, V., AND KIMBER, G. I959. Genetic control of chromosome pairing in intergeneric hybrids with wheat. Nature, Lond., 183 , I 244 -1 246.

RILEY, R., CHAPMAN, V., AND KIMBeR, G. 196o. Position of the gene determining the diploid-like meiotic behaviour of wheat. Nature, Lond., 186, 259-26o.

RILEY, R., KIMBER, G., AND CHAPMAN, v. I96ז. The origin of the genetic control of the diploid-like behaviour of polyploid wheat. (In the press).

RILEY, R., UNRAU, J., AND Ghapman, V. 1958. Evidence on the origin of the $\mathbf{B}$ genome of wheat. J. Hered., 49, 91-99.

SARKAR, P., AND stebbins, G. L. I956. Morphological evidence concerning the origin of the B genome of wheat. Amer. F. Bot., 43, 297-304.

SEARs, E. R. 1941. Chromosome pairing and fertility in hybrids and amphidiploids in the Triticinæ. Res. Bul. Mo. Agric. Exp. Sta., 337.

SEARS, E. R. 1948. The cytology and genetics of the wheats and their relatives. Adv. Genet., 2, 239-270.

SEARs, E. R. 1954. The aneuploids of common wheat. Res. Bul. Mo. Agric. Exp. Sta., 572.

SEARs, E. R. 1958. The aneuploids of common wheat. Proc. First Int. Wheat. Genet. Symp., $22 \mathrm{I}-228$.

SEARS, E. R., AND OKAMото, M. 1957. Genetic and structural relationships of nonhomologous chromosomes in wheat. Proc. Int. Genet. Symp. 1956, Supl. vol. Cytologia, 332-335.

SEARS, E. R., AND OKAMOTO, M. 1958. Intergenomic chromosome relationships in hexaploid wheat. Proc. Ioth Int. Cong. Genet., 2, 258-259.

SKovsted, A. 1937. Cytological studies in cotton. IV. Chromosome conjugation in interspecific hybrids. 7. Genet., 34, 97-1 34 .

STEBbins, G. L. 1950. Variation and evolution in plants. Oxford University Press.

TANAKA, M. 1955. Chromosome pairing in hybrids between AEgilops sharonensis and some species of Egilops and Triticum. Wheat Inf. Service, 2, 7-8.

tutin, т. G. 1952. Origin of Poa annua L. Nature, Lond., I69, I6o.

TUtin, T. G. I957. A contribution to the experimental taxonomy of Poa annua L. Watsonia, 4, I-Io.

U, N. 1935. Genome analysis in Brassica with special reference to the experimental formation of B. napus and peculiar mode of fertilisation. Fap. F. Bot., 7, 389-452. UPсотт, м. 1939. The nature of tetraploidy in Primula kewensis. F. Genet., 39, 79-1 oo. waddington, c. H. 1950. An Introduction to Modern Genetics. George Allen \& Unwin, Ltd., London. 